\title{
Chinese School Physical Education Ideas analysis and Countermeasures Background of the "Strong Sports Country" Strategy
}

\author{
Liu MingChang \\ P.E Department Hua zhong Agriculture university \\ Wuhan China \\ e-mail: lmc-107@mail.hzau.edu.cn
}

\author{
Chen HuaJie \\ Physical Education Department of Jing gangshan \\ University \\ Ji An China \\ e-mail: Chenhuajie@163.com
}

\begin{abstract}
Era after the Olympic, background of build the "strong sports country". Through the investigation and analysis on the current of school physical education thought, combining the current of school physical education, it should strengthen comprehensive, humanistic permeability, Bases on the students' physical and psychological health. To make our country school sports reform to the further development,provide beneficial enlightenment for making our country change from "big sports country" to "strong sports country".
\end{abstract}

Keywords-Strong sports country; School Physical education; Education thought; Lifelong sports

\section{INTRODUCTION}

At present, with the deepening of "sports power" and the gradual advancement of the reform of school physical education in China, the thoughts of school physical education are also diversified, which just as "all flowers bloom together", "contention of a hundred schools of thought". A variety of sports teaching thought and theory complement each other, provideing a broader space a comprehensive and healthy development of the school physical education. But the school sports teaching guidelines more than exert theoretical influence, effectively guiding and impacting the selection,approach and means of teaching in the practical teaching process of teaching and the evaluation of teaching effects, etc. The implementation, to a great extent, also has effects on the acceleration from "a major sports country”to “a world sports power”of China. Type Style and Fonts

\section{OBJECT AND METHOD}

A: The research object: a total of 20 representative colleges, primary schools and high schools;in the main, universities of Hubei province;

B:The research methods:

Literature: refering to literatures on the teaching thought of school physical education through the websites of periodicals.

Questionnaire: handing out a total of 200 questionnaires to administrators of school physical education and sports teachers, 191 recycled, the recovery rate 95.5\%, effective questionnaires 188 and efficiency rate $98.4 \%$; a total of 400 questionnaires were issued to students, 378 were recycled, the recovery rate $94.5 \%$, effective questionnaires 366 and efficiency rate $96.8 \%$.

Interview: interviewing school Sports administrators and experienced teachers to obtain first-hand materials.

\section{COMPARISON OF THE GUIDING IDEOLOGY OF DOMESTIC AND FOREIGN SPORTS TEACHING AT THE PRESENT STAGE}

School physical education ideology reflects the requirements for talent training of school sports and national educational development in the specific period, which plays a leading role in the teaching of physical education. The guiding ideology restricts the development orientation and level of sports teaching to a great extent, which is crucial to the development of school physical education.

Japan, which attaches importance to the ability of lifelong physical education of students, is the first country that has put forward "Life Sports"in the world. "Lifelong physical training ability, enhancing relaxation and happiness in sports and promoting physical and mental development is the core of the guiding ideology of physical education in Japan." [1]

The school sports development in Britain is the longest in the world and also more mature. Its specific aristocratic culture background determines that its ideology of school sports education is to cultivate students the "Knight" and "Count" characteristics.The school sports development in Britain advocates the comprehensive development, trains students the spirit of collectivism, and emphasizes the importance of indoctrination and dissemination of sports culture. China's economic development and the thousands of years of traditional culture exert a great influence on the development of physical education and sports guiding ideology. China's physical education ideology and is constantly being enriched and improved. For all the time, "China's school physical education thought, method and concept are still in the original model, lacking openness of the society and understanding of the concept of competition, the market consciousness and incentive mechanism. From the running thought, approaches to mechanism of 
management and operation , school physical education always fail to get rid of the passive situation" [1] but "sports power", to a large extent, changed the status quo the 2008 Beijing Olympic Games.

The present guiding ideology of school sports in China can be summed up as "lifelong physical education", "health comes first”, "quality-orientendeducation”, "physical education”, "skill-orientend education”, "happy sports” etc, and "active sports", "success sports" as the guiding principle. These guidelines in different periods respectively run through the development of school physical education reform in China.

\section{RESULT AND ANALYSIS OF THE SURVEY}

Every kind of teaching thought is distinct from each other, but also mutually interactive, " the existance of multiple theories does not mean that they are in conflict, nor does it means that we have to make a choice among them. Instead, they are complementary rather than contradictory"[2] With the in-depth development of national fitness campaign,different guiding ideology of school physical education also puts forward higher requirements to the school physical education. School physical education must "lifetime sports as the teaching guiding ideology, for physical education teaching goal has become the most fundamental objective of school physical education. In the sports teaching the use of certain guiding ideology, should integrate training on physical education, master of knowledge and skills, with cultivation of abilities to promote students'all-round development." [3]

The Statistical Table of Understanding of College Sports Curriculum

\begin{tabular}{lcccc}
\hline Options & Numbers & \multicolumn{1}{c}{ Frequency } & Ranking \\
Education on Skill & 138 & $73.4 \%$ & 2 & \\
Physical Education & 84 & $44.7 \%$ & 4 & \\
Sports Teaching for Happiness 54 & $28.7 \%$ & 5 & \\
Lifelong Sports Teaching & 168 & $89.4 \%$ & 1 & \\
Comprehensive Education & 108 & $57.4 \%$ & 3 &
\end{tabular}

Teachers of Physical Education's understanding on sports guiding ideology is discrete to some extent. The vast majority of teachers holds an identity view on lifelong sports. Indeed, as an important stage of students'life-long sports, the main function of school sports is to serve students's life-long sports, for students will eventually return to society, school is just one part of all life, school education should provides service for social work and life, the school sports should consider the needs of students' lifelong physical education, whose teaching content and mode, and methods should regard students's lifelong sports as the fundamental starting point.

\section{THE GUIDING IDEOLOGY OF CHINA'SSCHOOL PHYSICAL EDUCATION AT CURRENT STAGE}

A“Education on Skill”
Influenced by the Soviet Union, the emphasis on skill education of schools, the sports teaching goal is set as the master of motion technics and the formation of motion skills. In this case, "school physical education regards teaching as the center, the “qualified'”as purpose, sports teaching develops in the direction of competitiveness, ignoring the cultivation of student's sports interest, thus eventually affecting the goal of school sports at the present stage. Hence the formation of school sports teaching mode with sports skill teaching as the center."

B"Physical Education"

In a fairly long period, "Physical education is for physical education's sake" has been widely recognized in the whole sports academia, embodies the view of "effectively enhancing the physical fitness of students is the basic mission of school sports teaching" . With the development of the times, in most schools, sports administrators, researchers and the first-line workers agree with physiological, psychological, and social adaptive multidimensional values.on sports. Non-intellectual factors including emotional experience, personality development can not be ignored in sports teaching, instead, researches on school physical education from multidimensional perspective should be advocated, which is of positive significance to improve the overall quality of students.

C"Sports Teaching for Happiness"

"Sports Teaching for Happiness" is to pay attention to students' psychological experience in physical education teaching and actively create a pleasant teaching atmosphere. At present, there are several different understandings of the teaching mode and teaching idea of "Sports Teaching for Happiness”. For instance, the basic viewpoint of Japan's "Sports Teaching for Happiness" is that the delightful experience of students'participation in sports activities should be the goal of physical education. Make students to fully understand the inherent culture of activities in the process of movement, to enjoy all the pleasant experience to briought by the body and mind, thus shaping a rich sports culture, and making the sports culture as the most important element in lifelong living, so as to promote the comprehensive development of students physical fitness. Another idea treats the process and emotional experiences as its method and means to achieve the teaching purpose.

Since now the school sports continue to promote the reform of quality education, "Sports Teaching for Happiness" has exerted great influence on school physical education in China. Under this influence, the consciousness of students participating the sports is promoted, and the physical education becomes popular with students, the basic reason of which lies in that students experience tremendous joy from the motion process, teaching methods and teaching content.

D“Comprehensive Education” as the Guiding Ideology

“'Comprehensive Education' refers to stimulating students moral, intellectual, physical development as the purpose, and the realization of the objectives of physical 
education teaching as the leading thought." [4] Its guiding ideology is to enhance students'physical quality as the basis, coordinate students' physical quality training with sports skills effectively, at the same time, instill social, moral and basic knowledge education in the whole process of sports teaching. "Comprehensive Education" is relative to the onesided education. As foe physical education in normal schools, school administrators often equal students'general learning of knowledge with training on and development of the overall quality, without using scientific and reasonable teaching methods, or means to promote the comprehensive and healthy development of students'mental quality in moral, intellectual, physical, asthetic, labour and other aspects.

E "Lifelong Sports Teaching”

"Lifelong Sports Teaching" refers to the cultivation of students' lifelong physical activity participation ability and habit as the starting point of the physical education. School physical education is the most important and decisive period of training on students lifelong sports, focusing on cultivating the students' lifelong physical exercise and learning awareness and habits, so as to grasp the basic theory and methods of physical exercise, to enhance physical fitness, to promote physical and mental health as the starting point and orientation, thus laying a good foundation for lifelong physical activity for students once they get out of the campus into society. The idea of lifelong physical education is inevitable transformation of physical education concept, which embodies the people-oriented philosophy, and also reflects the idea of school education in the future.This is a requirement for sports development in the new century and also an important part of "sports power strategy”, making "everyone take part in sports" win over support among people all the more, and gradually forming a good physical fitness and social atmosphere to set off a nationwide fitness.

\section{VI.UG GESTIONS}

A:School Physical Education Should be Based on the Overall Goal of "Educating People"

School physical education should "adapt and meet the wide differences in characteristics and needs of students, giving students more rights of participation, taking students as the subject of education and highlighting humane care for the students," [5] moreover, give full play to the functions of sports, especially pay attention to the combination of "physical education” and "education for people”, and focus on training of students' social adaptability, competitiveness, creativity and willpower in the course of physical education. Improving the understanding, renewing ideas and strengthening physical education is an important part of the system of school education, as well as one of the main channel of cultural transmission and carrier of campus culture. Except "Educating People", school sports should also let students take the initiative to update the concept of physical education, form the habit of lifelong physical exercise, thus forming a good atmosphere for sports exercise in school and communities, and winning support of "Strong Sports Country” from the masses.

B School Physical Education Should Always Practise the guiding ideology "Health Comes First"

"Fully respect students' right of life, right of survival and right of development, "Health Comes First" as the guiding ideology of education should be carried out thoroughly in the sports teaching" [6]"Health Comes First" should always be carried out in the teaching practice of school physical education. Selection the teaching mode, teaching content and teaching methods of school physical education, should consider students' characteristics of physical fitness development, making them master a few sports special skill, at the same time, promoting the comprehensive development of their physical and mental quality. The most fundamental starting point is to create a good platform for the healthy growth of students, leting every student has a strong and hralthy body. Only each individual of the young students is keen on physical exercise, with a healthy body and perfect personality, can we have a healthy and vibrant nation and a real "sports power".

C:Strengthen the Infiltration of Humanism of School Physical Education, Take the Student as the Main body and Promote Students All-Round Development

School Physical Education takes the cultivation of students' humanistic qualities as a starting point in the selection of curriculum content and teaching form. In the sports teaching process, school physical education fully impart humanity. The development of teaching objectives, content, methods and classroom teaching arrangement should respect the needs of students. That "Setting up the idea of enhancing students' reality and future health by 'knowledge innovation' and 'health comes first', and school physical education should be based on the present and face the future". ${ }^{[7]}$ is the guiding ideology to truly put students in the subject status in learning, "'learning to learn' is is the important premise on "how to survive" in the future', 'learning to learn' is a major countermeasure for the future social development to adapt to the education and teaching." ${ }^{[8]}$ It also enables students to develop a good habit of self-learning and self-exercise. When they enter society, students can take exercises with scientific, effective methods in their lifetime.

\section{CONCLUSION}

“'Sports Power"” refers to social sports as the basis, competitive sports for the overall development of sports in all fields to a class and in the forefront in the nation in the world. It includes not only the competitive sports and mass sports, but also the sports science and technology, physical education, sports culture, sports venues, sports industry." [9] The whole school physical education plays an important role in the "sports power" strategy, the sports scientific research, sports fitness, sports culture and communication, 
the remodelingof fitness concept. The ideology of school physical education also determines that the function of school physical education is to highlight the main factors. The arragement and adaption to the development of school physical education under the new situation to is an important task facing the sports workers and has a long way to go.

\section{REFERENCES}

[1] Li Zhiquan Comparative Study on School Sports Teaching Guiding Ideology of China, Japan, the United States and Other Countries[J] School Education in China 2010.02 - 4

[2 ]K Merton Social Research and Social Policy [M] Lin Ju Ren Beijing: Joint Publishing Co. 1998: 91
[3] Liu Mingchang Research on Sports Curriculum and teaching model of Wuhan University [D] Nanjing Normal University

China master thesis database 2007

[4] Lan Zili\&Huang Wenren Reflection and on the School Sports Teaching Guidelines [J] Journal of Wuhan Sports Institute 2009.01 - 88.

[5] Yang Yaohua Enlightenment of Inclusive Education for School Physical Education[J] Journal of Shandong Sports Institute 2010.03-91.

[6] Zhao Jing On "Humanism" in modern Physical Education Teaching Thought [J]Fight Martial Arts Science 2009.10 - 93.

[7] Liu Mingchang Liu Hewang On demand of Sports Learning Subjects and Supply of Sports Teaching [J] Sichuan Sports Science 2010.01 - 124.

[8] Xie Limin Compendium of modern Teaching [M] Shaanxi People's Education Press, 1988:126

[9] Xu Benli The interpretation and analysis of Connotation of Sports Power, Competitive Sports Power, Mass Sports Power [J] Journal of Tianjin University of Sport, 2009, 24 (2): 93 